\title{
Motion - Cyclo-oxygenase-2 selective nonsteroidal anti-inflammatory drugs are as safe as placebo for the stomach: Arguments for the motion
}

\author{
Richard H Hunt MB FRCP FRCPEd FRCPC
}

\begin{abstract}
RH Hunt. Motion - Cyclo-oxygenase-2 selective nonsteroidal anti-inflammatory drugs are as safe as placebo for the stomach: Arguments for the motion. Can J Gastroenterol 2003;17(5):339-341.

Traditional nonsteroidal anti-inflammatory drugs (NSAIDs) are known to cause gastritis, gastric and duodenal ulcers, and gastrointestinal (GI) blood loss, as well as alterations in small bowel permeability. Patients at a high risk for these complications include those who are older than 60 years of age, those with a previous history of complicated peptic disease and bleeding, and those who take high dose or multiple NSAIDs, including low dose aspirin, corticosteroids or anticoagulants. The introduction of selective inhibitors of cyclooxygenase-2 (COX-2) has provided effective treatment of inflammatory arthritis and musculoskeletal pain, with dramatic reductions in the risk of GI adverse events. The two most widely prescribed coxibs are celecoxib and rofecoxib, and others are being developed. Endoscopic studies have revealed that coxibs are only half as likely to induce upper GI ulceration than are traditional NSAIDs, and are as safe as placebo. Furthermore, the newer drugs do not cause excessive blood loss from the GI tract and do not affect small bowel permeability. The Vioxx Gastrointestinal Outcomes Research Study (VIGOR) revealed that the incidence of myocardial infarction was significantly lower with naproxen than rofecoxib, although this study was not designed to look at this endpoint. Coxibs are an important addition to the pharmacotherapy of inflammatory disease.
\end{abstract}

Key Words: Adverse events; COX-2 selective inhibition; NSAIDs; Safety; Stomach
Motion : Les anti-inflammatoires non stéroïdiens sélectifs de la cyclo-oxygénase 2 sont aussi sûrs qu'un placebo pour l'estomac : Arguments en faveur de la motion

On sait que les anti-inflammatoires non stéroïdiens (AINS) peuvent causer une gastrite, des ulcères gastriques et duodénaux et une perte sanguine gastro-intestinale (GI), de même que des modifications à la perméabilité de l'intestin grêle. Les patients très vulnérables à ces complications sont les personnes très âgées, qui ont des antécédents de maladie ou d'hémorragie peptiques, qui prennent de multiples AINS, corticoïdes ou anticoagulants ou qui en prennent de fortes doses. L'arrivée des inhibiteurs sélectifs de la cyclo-oxygénase 2 (COX-2) a permis d'offrir un traitement efficace de l'arthrite inflammatoire et des douleurs musculosquelettiques tout en favorisant une diminution remarquable du risque d'effets secondaires GI. Les deux médicaments les plus prescrits sont le célécoxib et le rofécoxib. D'autres sont en cours d'élaboration. Les études endoscopiques révèlent que les coxibs risquent deux fois moins de provoquer des ulcérations gastro-intestinales que les AINS traditionnels et qu'ils sont tout aussi sûrs qu'un placebo. De plus, les nouveaux médicaments n'entraînent pas de perte sanguine excessive du tractus GI et ne nuisent pas à la perméabilité de l'intestin grêle. Selon l'étude de recherche de Vioxx sur les issues gastro-intestinales (VIGOR), l'incidence d'infarctus du myocarde était plus élevée avec l'un des inhibiteurs COX-2, le rofécoxib, qu'avec le naproxène, probablement parce que celui-ci inhibe le thromboxane dans les coronaires. Les coxibs représentent un ajout important à la pharmacothérapie des maladies inflammatoires.
$\mathrm{T}$ he gastroscopic demonstration of the toxicity of acetylsalicylic acid was first demonstrated a century ago and the gastrointestinal (GI) adverse effects of nonsteroidal anti-inflammatory drugs (NSAIDs) have been reported increasingly in the literature ever since (1-4). These agents are undoubtedly effective in the treatment of joint inflammation and musculoskeletal injury, but a significant proportion of patients experience upper GI symptoms, usually dyspepsia, and endoscopic lesions ranging from petechial hemorrhages to bleeding peptic ulcers.

The risk of developing a severe GI adverse event varies from patient to patient, and from NSAID to NSAID. Numerous epidemiological studies have shown that the use of these drugs increases the overall risk of peptic ulcer bleeding
(OR 3.09-4.5), adverse events-related hospitalization (OR 3.9. 5.5), GI surgery (OR 7.75) and GI adverse events-related death (OR 4.79-7.62) (1-3). Certain risk factors predispose NSAID users to a greater risk of developing a severe GI complication. These risks include age over 60 years (OR 2.86), previous history of ulcer disease or ulcer bleeding (OR 4.76-9.5), use of high-dose or multiple NSAIDs (OR 4.0-23.3), concomitant corticosteroid therapy (OR 1.83-4.4) and concomitant anticoagulant therapy (OR 2.1-16.0).

Many drugs have been developed in attempts to minimize these adverse effects, with varying degrees of success and acceptance. Several classes of NSAIDs are available, including propionic acids, anthranilic acids, salicylic acids, acetic acids, oxicams, naphthylalkanones and cyclo-oxygenase-2 (COX-2)

This article was originally presented at a symposium entitled, "Controversies in Gastroenterology", sponsored by Axcan Pharma, Toronto, Ontario, April 8 to 10,2002

Division of Gastroenterology, McMaster University Medical Centre, Hamilton, Ontario

Correspondence: Dr Richard H Hunt, Division of Gastroenterology, McMaster University Medical Centre, 1200 Main Street West,

Room 4W8A, Hamilton, Ontario L8N 325. Telephone 905-521-2100 ext 73219, fax 905-521-5072, e-mail huntr@mcmaster.ca 
selective inhibitors. Results from the Arthritis, Rheumatism, and Aging Medical Information System (ARAMIS) database of adverse events and meta-analysis have shown that, among the conventional NSAIDs, ibuprofen and salsalate are the least toxic, whereas tolmetin, fenoprofen, indomethacin, piroxicam, ketoprofen and azapropazone are among the most toxic to the GI tract $(3,5)$.

More recent studies have shown that some of the newer NSAIDs, specifically nabumetone, meloxicam and etodolac produce significantly fewer peptic ulcer bleeds than do other agents (6-8). Consequently, it has been suggested that there is a correlation between the risk of GI complications and relative degree of inhibition of COX-1 and COX-2 isoenzymes $(9,10)$. In other words, a more selective inhibition of COX-2 compared with COX-1 is associated with a decreased risk of adverse GI events. The published ratios of the effects of various conventional NSAIDs on COX-2 and COX-1 may not be accurate, however, because of significant variability in the assay methods that have been used. Nevertheless, the GI toxicity of the highly selective COX-2 inhibitors, celecoxib (Celebrex, Searle, Mississauga, Ontario) and rofecoxib (Vioxx, Merck Frosst, Kirkland, Quebec), and of newer coxibs that are being developed, valdecoxib and etoricoxib, appears to be minimal.

Studies of safety for the digestive tract have been an essential component of the development of new anti-inflammatory drugs (11). Extensive safety studies for selective COX-2 inhibitors have been conducted and have involved the detection of microscopic quantities of blood in the stool using the ${ }^{51}$ Chromium-labeled fecal red blood cell loss method (12); macromolecular permeability of the small intestine (13); endoscopic examination of the upper GI tract (14-16); and assessment of relevant clinical outcome measures, such as the presence of ulcers, perforation or bleeding (15-19). These studies have shown conclusively that patients who are taking a coxib experience significantly lower rates of gastric and duodenal ulcers, and of bleeding ulcers, than do patients taking conventional NSAIDs. The reduction in risk is approximately $50 \%$ for perforations, ulcers and upper GI bleeds.

Other types of studies have also demonstrated the safety of coxibs. In contrast to ibuprofen, the amount of bleeding, as measured by ${ }^{51}$ Chromium-labeled fecal red cell loss, is similar between rofecoxib and placebo (12). Similarly, rofecoxib does not cause the abnormalities in small intestinal permeability, as

\section{REFERENCES}

1. Gabriel SE, Jaakkimainen L, Bombardier C. Risk for serious gastrointestinal complications related to use of nonsteroidal anti-inflammatory drugs. A meta-analysis. Ann Intern Med 1991;115:787-96.

2. MacDonald TM, Morant SV, Robinson GC, et al. Association of upper gastrointestinal toxicity of non-steroidal anti-inflammatory drugs with continued exposure: cohort study. BMJ 1997;315:1333-7.

3. Garcia Rodriguez LA. Nonsteroidal anti-inflammatory drugs, ulcers and risk: a collaborative meta-analysis. Semin Arthr Rheum 1997;26(Suppl 1):16-20.

4. McCarthy D. Nonsteroidal anti-inflammatory drug-related gastrointestinal toxicity: Definitions and epidemiology. Am J Med 1998;105:3S-9S.

5. Singh G, Rosen Ramey D. NSAID induced gastrointestinal complications: the ARAMIS perspective - 1997. Arthritis, Rheumatism, and Aging Medical Information System. J Rheumatol Suppl 1998;51:8-16.

6. Rothstein R. Safety profiles of leading nonsteroidal anti- assessed by ${ }^{51}$ Chromium-EDTA and L-rhamnose absorption, that are seen with ibuprofen (13).

Short term endoscopic studies have shown that selective COX-2 inhibitors induce significantly less gastric mucosal damage than do naproxen or ibuprofen, and are similar to placebo. Even at doses that are two to four times higher than those known to be effective for the treatment of osteoarthritis, rofecoxib is as safe as placebo with respect to GI blood loss (12). Endoscopic studies involving patients with rheumatoid arthritis or osteoarthritis (including patients who are at high risk because of advanced age or history of ulcer disease) have shown that rofecoxib causes significantly fewer ulcers than either naproxen or ibuprofen, and the same number as placebo $(14-16,18,20)$.

Low rates of endoscopically confirmed ulcers and complications with coxibs have been confirmed by the Celecoxib LongTerm Arthritis Safety Study (CLASS ) (21) and the Vioxx Gastrointestinal Outcomes Research Study (VIGOR) (22). The latter study, which enrolled more than 8000 patients with rheumatoid arthritis, found that rofecoxib produced $54 \%$ fewer clinical upper GI events, 57\% fewer complicated upper GI events, and $62 \%$ fewer episodes of GI bleeding from any site in the GI tract than did naproxen. The risk reduction was especially dramatic in patients with more than one risk factor (RR $0.49,95 \%$ CI 0.32 to 0.65 ), compared with those with no risk factors (RR 0.12, $95 \%$ CI 0.04 to 0.98). The risk of ulcer disease in these low risk patients is close to baseline, but is not zero. This is because the background prevalence of ulcer disease is approximately $7 \%$, although this might be expected to fall in the future because of the decreasing prevalence of Helicobacter pylori in the general population.

The VIGOR study revealed a slight but significantly lower rate of myocardial infarction in patients taking naproxen $(0.1 \%)$ compared with those taking rofecoxib (0.4\%) (22). This effect has been attributed by some to the protective effect of naproxen, which results in a roughly $95 \%$ inhibition of thromboxane synthesis, an effect similar to that of aspirin.

The introduction of COX-2-selective agents offers the opportunity for the safe and effective treatment of patients who are at high risk of developing GI complications. Large, long term, randomized, controlled studies are underway to confirm the safety of these agents, particularly in organs outside of the GI tract.

inflammatory drugs. Am J Med 1998;105:39S-43S.

7. Schoenfeld P. Gastrointestinal safety profile of meloxicam: A metaanalysis and systematic review of randomized controlled trials. Am J Med 1999;107:48S-54S.

8. Huang J-Q, Sridhar S, Hunt RH. Gastrointestinal safety profile of nabumetone: A meta-analysis. Am J Med 1999;107:55S-61S.

9. Hawkey CJ. COX-2 inhibitors. Lancet 1999;353:307-14.

10. Warner TD, Giuliano F, Vojnovic I, Bukasa A, Mitchell JA, Vane JR. Nonsteroid drug selectivities for cyclo-oxygenase-1 rather than cyclo-oxygenase-2 are associated with human gastrointestinal toxicity: A full in vitro analysis. Proc Natl Acad Sci USA 1999;96:7563-8

11. Blower AL. Considerations for nonsteroidal anti-inflammatory drug therapy: Safety. Scand J Rheumatol 1996;105:13-24.

12. Hunt RH, Bowen B, Mortensen ER, et al. A randomized trial measuring fecal blood loss after treatment with rofecoxib, ibuprofen, or placebo in healthy subjects. Am J Med 2000;109:201-6.

13. Sigthorsson G, Crane R, Simon T, et al. COX-2 inhibition with 
rofecoxib does not increase intestinal permeability in healthy subjects: a double blind crossover study comparing rofecoxib with placebo and indomethacin. Gut 2000;47:527-32.

14. Laine L, Harper S, Simon T, et al. Rofecoxib Osteoarthritis Endoscopy Study Group. A randomized trial comparing the effect of rofecoxib, a cyclooxygenase 2-specific inhibitor, with that of ibuprofen on the gastroduodenal mucosa of patients with osteoarthritis. Gastroenterology 1999;117:776-83.

15. Simon LS, Weaver AL, Graham DY, et al. Anti-inflammatory and upper gastrointestinal effects of celecoxib in rheumatoid arthritis: a randomized controlled trial. JAMA 1999;282:1921-8.

16. Langman MJ, Jensen DM, Watson DJ, et al. Adverse upper gastrointestinal effects of rofecoxib compared with NSAIDs. JAMA 1999;282:1929-33.

17. McMahon AD, Evans JM, White G, et al. A cohort study (with resampled comparator groups) to measure the association between new NSAID prescribing and upper gastrointestinal hemorrhage and perforation. J Clin Epidemiol 1997;50:351-6.

18. Watson DJ, Harper S, Zhao P, Bolognese J, Simon T, Seidenberg B. Treatment with rofecoxib required less gastrointestinal (GI) $\mathrm{CO}_{-}$ medication and fewer GI procedures than non-specific cyclo- oxygenase inhibitors (NSAIDs). Arthr Rheum 1999;42:S1996. (Abst)

19. Laine L, Bombardier C, Hawkey C, Shapiro D, Reicin A. Influence of $\mathrm{H}$ pylori and other potential risk factors on clinical GI events in a double-blind outcome study of rofecoxib vs. naproxen. Gastroenterology 2000;118:A862. (Abst)

20. Goldkind L. Medical Officer's Gastroenterology Advisory Committee Briefing Document. Arthritis Advisory Committee Meeting, Feb 7th, 2001, FDA Transcripts (Celebrex): <www.fda.gov/ohrms/dockets/ac/01/briefing/3677b1.htm> (Version current at April 8, 2003)

21. Silverstein FE, Faich G, Goldstein JL, et al. Celecoxib Long-term Arthritis Safety Study. Gastrointestinal toxicity with celecoxib vs nonsteroidal anti-inflammatory drugs for osteoarthritis and rheumatoid arthritis: the CLASS study: A randomized controlled trial. JAMA 2000;284:1247-55.

22. Bombardier C, Laine L, Reicin A, et al. VIGOR Study Group. Comparison of upper gastrointestinal toxicity of rofecoxib and naproxen in patients with rheumatoid arthritis. $\mathrm{N}$ Engl J Med 2000;343:1520-8. 


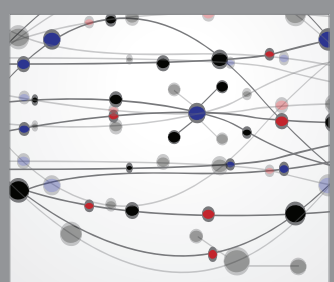

The Scientific World Journal
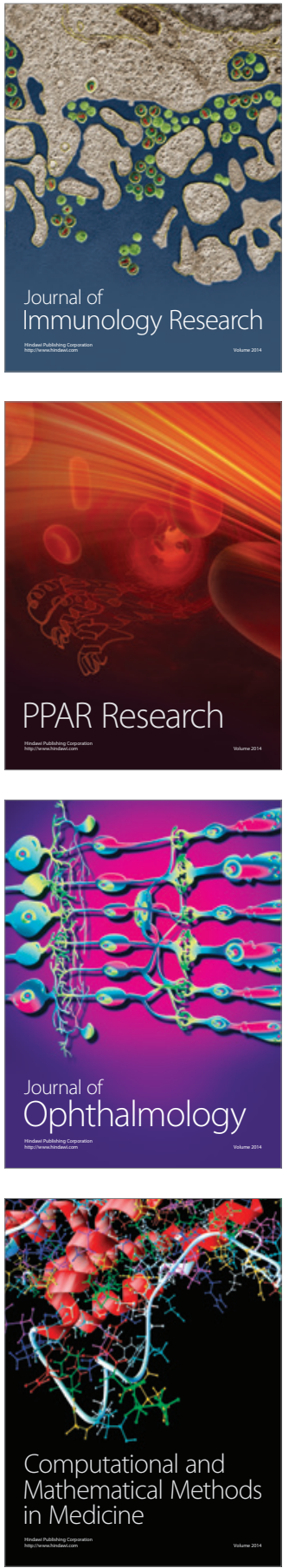

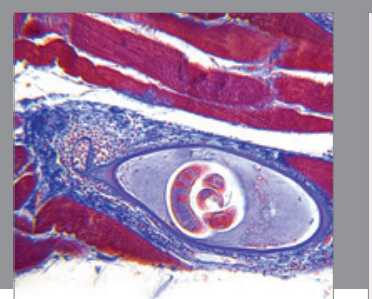

Gastroenterology Research and Practice

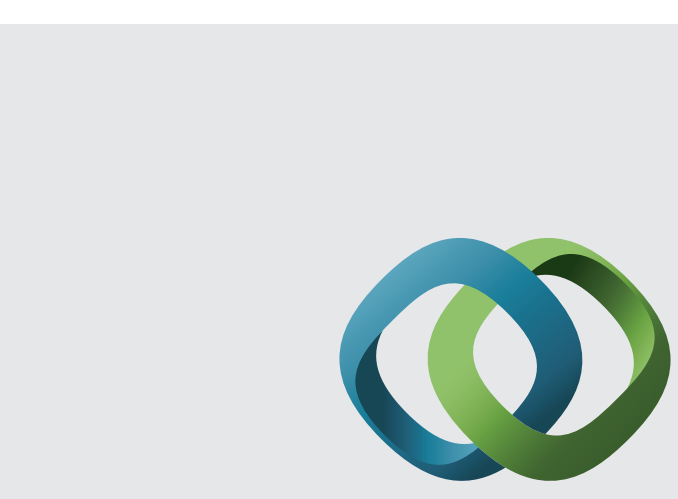

\section{Hindawi}

Submit your manuscripts at

http://www.hindawi.com
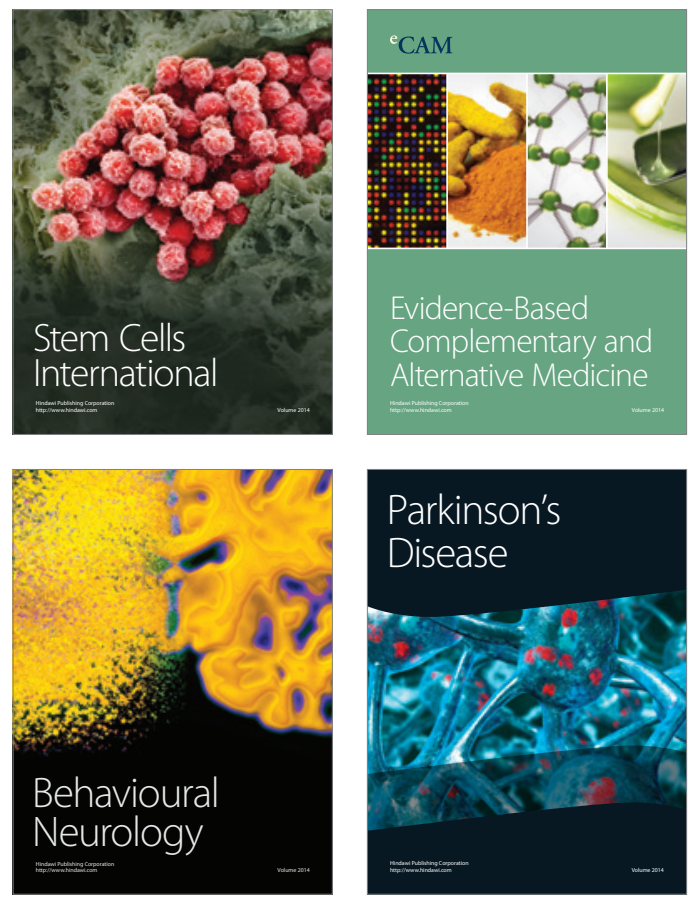
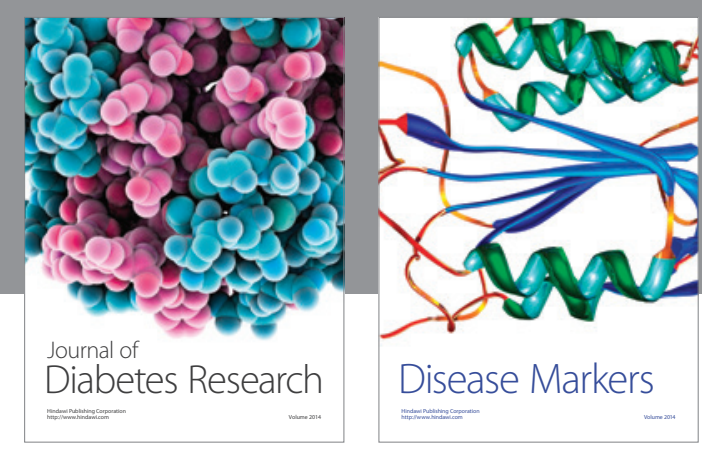

Disease Markers
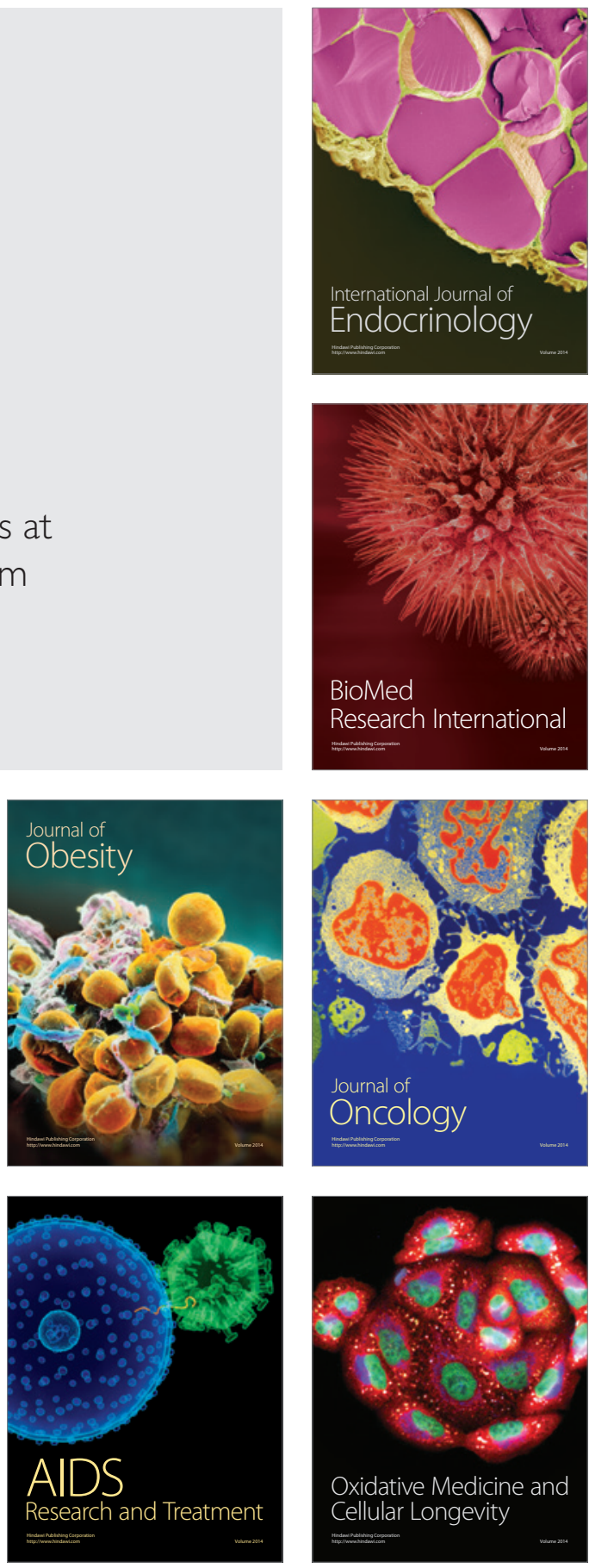